\title{
Gastric emptying: a contributory factor in gastro-oesophageal reflux activity?
}

G Stacher, J Lenglinger, H Bergmann, C Schneider, M Hoffmann, G Wölfl, G Stacher-Janotta

\begin{abstract}
Aims-To evaluate the impact of total and proximal stomach emptying on 24 hour and postprandial reflux as well as the number of reflux episodes per hour in relation to the impact of lower oesophageal sphincter (LOS) pressure, and oesophageal contractile and clearance function.

Methods-Seventy one outpatients (37 female, 34 male; age 23-82 years) with symptoms suggestive of both delayed gastric emptying and reflux referred for further investigations participated in the study. Gastric emptying of a semisolid $1168 \mathrm{~kJ}$ meal and oesophageal clearance of a water bolus (supine) were recorded scintigraphically, reflux by 24 hour pH monitoring, and oesophageal motility manometrically.
\end{abstract}

Results-Slow proximal but not slow distal or total stomach emptying correlated with increased 24 hour and postprandial acid exposure and increased number of reflux episodes/hour. No relationship was found between total or proximal emptying and LOS resting pressure, oesophageal contraction amplitude, percentage of failed contractions, or clearance. Multiple linear regression analyses showed that slow proximal emptying and low LOS pressure contributed significantly to both 24 hour ( $p=0.0007$ and $p=0.0001)$ and two hour postprandial acid exposure $(p=0.007$ and $p=0.0001$ ). In contrast, the rate of total emptying contributed to neither 24 hour nor postprandial acid exposure.

Conclusion-Our data suggest that in contrast with total stomach emptying, the rate of proximal stomach emptying contributes to the extent of 24 hour as well as postprandial acid exposure and the number of reflux episodes/hour.

(Gut 2000;47:661-666)

Keywords: gastro-oesophageal reflux; gastric emptying; proximal stomach; lower oesophageal sphincter; oesophageal motor activity; oesophageal clearance

Delayed gastric emptying of ingesta may result in gastric distension and thereby a heightened propensity to transient relaxations of the resting pressure of the lower oesophageal sphincter $(\mathrm{LOS})^{1}$ which in turn may cause increased gastro-oesophageal reflux. ${ }^{2}$ A series of previous investigations revealed delayed gastric emptying of solid meal components as well as liquids in a proportion (28-56\%) of patients with reflux disease. ${ }^{3-9}$ In one study, however, only two of 33 patients had delayed emptying of solids and liquids. ${ }^{10}$ In a further investigation carried out in 76 patients with heartburn, regurgitation, or both, and in 38 asymptomatic subjects, delayed emptying of oatmeal porridge occurred with equal frequency in individuals with and without reflux. ${ }^{11}$ Patients with reflux oesophagitis were found to empty their stomach slower than healthy subjects in four investigations, ${ }^{681213}$ but no such difference was revealed in three others. ${ }^{1014}{ }^{15}$ Two groups ${ }^{16} 17$ assessed the relationship between gastric emptying of liquid and reflux in infants and children. Both reported the extent of reflux in the postprandial phase, but not over the entire 24 hour monitoring period, to be related to emptying rate. One study suggested that the rate of emptying of the proximal part but not the distal part of the stomach played a crucial role in the occurrence of transient LOS relaxations and thus the extent of reflux after a meal. ${ }^{18}$

The aim of the present study was to assess the impact of the emptying rate of the entire stomach and of the proximal and distal stomach, in adult patients with symptoms of both delayed gastric emptying and reflux, on 24 hour and postprandial acid exposure. We also investigated the number of reflux episodes per hour as an indicator of transient LOS relaxations ${ }^{19}$ in relation to the impact of factors with an established role in reflux disease (that is, LOS resting pressure, contractile activity of the oesophageal body, and clearance function of the oesophagus).

\section{Methods}

PATIENTS

Seventy one outpatients with symptoms indicative of both reflux (such as heartburn, acid regurgitation, and retrosternal pain) and delayed gastric emptying (such as (postprandial) epigastric fullness or discomfort, early satiety, and belching) were studied. All had been referred for further investigation of upper gastrointestinal function to the Psychophysiology Unit. Thirty seven were female and 34 male; age ranged from 22.9 to 81.8 years (mean 50.8 (SEM 1.6)) and body mass index (BMI) from 16.0 to $36.3 \mathrm{~kg} / \mathrm{m}^{2}$ (mean 25.8 (0.5)). None had other diseases, had undergone operations, or was receiving any drug which could have interfered with gastro-

Abbreviations used in this paper: $\mathrm{AUC}_{\mathrm{to}}, \mathrm{AUC}_{\mathrm{prox}}$ $\mathrm{AUC}_{\text {dist }}$ area under emptying curve of total, proximal, and distal stomach; BMI, body mass index; LOS, lower oesophageal sphincter 
intestinal motility or reflux activity. Sixty one patients had undergone oesophagogastroscopies 1-8 weeks before and three underwent this procedure 2-4 weeks after the investigations indicated below: 26 had no oesophagitis and 38 had oesophagitis of grades I-IV according to Savary and Miller. ${ }^{20}$

PROCEDURE

Assessments of gastric emptying, oesophageal motor and gastro-oesophageal reflux activity, and oesophageal bolus transport were carried out over three consecutive weeks. All recordings took place, or were started, in the morning with patients having finished their last meal no later than $8.00 \mathrm{pm}$ on the preceding day. Studies of oesophageal motility were followed immediately by a 24 hour assessment of reflux and, within one week, an assessment of oesophageal bolus transport; gastric emptying was recorded in five patients before and in 66 after these procedures. Gastric emptying and oesophageal manometric and $\mathrm{pH}$ metric studies were performed on separate days so as not to interfere with the patients' customary eating patterns and related reflux activities. The investigation was performed in accordance with the Declaration of Helsinki, as revised in 1996.

ASSESSMENT OF GASTRIC EMPTYING

Emptying of a semisolid $1168 \mathrm{~kJ}$ meal was recorded scintigraphically. ${ }^{21}$ The meal comprised $250 \mathrm{ml}$ of milk (9.2 g fat, $8.5 \mathrm{~g}$ protein, $12.3 \mathrm{~g}$ carbohydrates), $15 \mathrm{~g}$ of sugar, $14 \mathrm{~g}$ of maize starch (11.9 g carbohydrates) and, for flavouring, cinnamon. The meal was cooked until a semisolid consistency was reached and, after cooling to a temperature at which it could be eaten, mixed with $60 \mathrm{MBq}\left[{ }^{99 \mathrm{~m}} \mathrm{Tc}\right.$ ] phytate in isotonic saline. The $\left[{ }^{99 \mathrm{~m}} \mathrm{Tc}\right]$ radiolabel is bound reliably to the meal and remains so for at least two hours. ${ }^{21}$ Recording began at the end of ingestion and lasted for 50 minutes. Patients sat in an armchair tilted $30^{\circ}$ backwards to avoid overprojection of the stomach and small intestine. A posteriorly located gamma camera (GCA901A, Toshiba Medical Systems, Tokyo, Japan) was used. Serial images over one minute each were acquired in frame mode. Over an image obtained by summing up all the one minute images, a region of interest was drawn, including the entire stomach. To evaluate emptying from the fundus and proximal corpus on the one hand and the distal corpus and antrum on the other, the whole stomach region was subdivided into two regions: (a) the proximal stomach, defined as the reservoir area seen for at least the first minutes after meal ingestion and (b) the remainder of the stomach. ${ }^{22}$ Counts in these regions were corrected for variation in tissue attenuation caused by the changing intragastric position of the meal and use of a single headed camera, as well as for background activity and radionuclide decay. For each region (total, proximal, and distal), activity-time curves expressed as percentages of counts in the total stomach region immediately after ingestion were derived. Areas under the activity-time curves $\left(\mathrm{AUC}_{\mathrm{tot}}, \mathrm{AUC}_{\mathrm{prox}}\right.$,
$\left.\mathrm{AUC}_{\text {dist }}\right)$ were calculated as overall measures of emptying. The radiation burden was $1.7-5.4$ millisievert (that is, less than from a barium contrast investigation). The criterion for delayed emptying was an $\mathrm{AUC}_{\text {tot }}>4609$ unitsthat is, more than the 95th percentile of the AUC $_{\text {tot }}$ of 68 healthy, symptom free subjects (10 female, 58 male; mean age 32.0 (SEM 1.5) years; mean BMI $\left.22.8(0.4) \mathrm{kg} / \mathrm{m}^{2}\right)$.

The reproducibility and reliability of the assessment of proximal and distal stomach emptying was tested in 24 patients ( 15 female, nine male; aged $21-76$ years, median 42 ), who had undergone two emptying studies each, 7-781 days apart (median 42 days). None had participated in the present study. In a file containing the data recorded on the two occasions, individual studies were arranged in random order and patient names as well as recording dates made illegible. Each emptying study contained in the blinded data file was then assessed independently by two observers according to the above mentioned criteria. The results of their assessments were subjected to variance component analysis (SAS, Proc VARCOMP) accounting for the influence of the random factors patient (1-24), recording day $(1,2)$, observer (1, 2), and the interaction patient $\times$ observer. It was found that the factors patient and recording day accounted for $56 \%$ and $25 \%$, respectively, of the variance, whereas the factor observer accounted for $<1 \%$. Thus the variability between the readings of the two observers was negligible in relation to the large variability between patients and recordings in one patient made at different times. A linear regression of the average of the absolute differences between the assessments of the recordings on the two days (as averaged over the two observers) on the time interval between the recording days did not show a noticeable relationship $(r(22)=-0.010 ; \mathrm{p}=0.618)$. Hence the variability of assessments between days was similar irrespective of the interval between recordings. Taken together, the technique used for assessing proximal and distal stomach emptying can be regarded as highly reproducible and reliable.

ASSESSMENT OF GASTRO-OESOPHAGEAL REFLUX Reflux was recorded by ambulatory 24 hour $\mathrm{pH}$ monitoring. Antimony electrodes and fitting recorders (Synectics Medical, Stockholm, Sweden) were used. The percentage of time with $\mathrm{pH}<4$ in the total 24 hour recording period (24 hour acid exposure) and in the period from the start of meal ingestion to two hours thereafter (postprandial acid exposure) as well as the DeMeester score ${ }^{23}$ were determined. The number of reflux episodes/hour was used as an indirect measure of transient LOS relaxations, ${ }^{19}$ although the actual number of transient relaxations may be underestimated as not all such relaxations are associated with reflux and as the computer analysis does not detect reflux episodes occurring at an oesophageal $\mathrm{pH}<4$. For 24 hour reflux, a DeMeester score of $>14.72$ was considered pathological. ${ }^{23}$ 
ASSESSMENT OF OESOPHAGEAL MOTILITY

Patients were studied in the supine position with their head resting on a pillow. A probe fitted with five strain gauge pressure sensors at $3 \mathrm{~cm}$ intervals (Konigsberg Instruments, $\mathrm{Pa}-$ sadena, California, USA) was used. The most distal sensor was circular and the remaining four were oriented radially $90^{\circ}$ apart; their output was recorded using a computer based system (PC-Polygraf; Synectics). Initiation of swallowing was monitored by a microphone attached laterally to the thyroid cartilage. LOS resting pressure and its relaxation on swallowing $5 \mathrm{ml}$ of water were determined by pulling the probe in $5 \mathrm{~mm}$ steps in $30 \mathrm{~s}$ intervals and using end expiratory mean fundic pressure as the zero reference. For evaluation of swallow initiated pressure waves in the oesophagus, the probe was withdrawn in $1 \mathrm{~cm}$ steps and $30 \mathrm{~s}$ intervals. At each step, the patient swallowed 5 $5 \mathrm{ml}$ of water. Mean amplitude of the swallow initiated pressure waves in the distal, middle, and proximal third of the oesophagus and percentage of failed contractions (that is, swallow initiated contractions of an amplitude $>10$ $\mathrm{mmHg}$ not reaching the distal third of the oesophagus) were determined. Recordings were analysed visually with the help of a computer program (Synectics).

\section{QUANTIFICATION OF OESOPHAGEAL BOLUS}

TRANSPORT (CLEARANCE)

Patients were positioned supine beneath a gamma camera fitted with a high sensitivity parallel hole collimator; the field of view included the mouth and epigastrium. Patients were instructed to swallow $10 \mathrm{ml}$ of water in a single gulp and not to swallow again until asked to do so after $120 \mathrm{~s}$. The bolus was labelled with $20 \mathrm{MBq}$ of $\left[{ }^{99 \mathrm{~m}} \mathrm{Tc}\right]$ phytate and instilled into the mouth by a syringe. Radioactivity was recorded for 40 seconds at 5 frames/s and in the following 80 seconds at 1 frame $/ 5 \mathrm{~s}$. Using a $\left[{ }^{57} \mathrm{Co}\right]$ marker over the cricoid and activity in the oesophagus and gastric fundus as landmarks, regions of interest were drawn representing the oropharynx, and proximal, middle, and distal third of the oesophagus and fundus. For each region, an activity-time curve was

Table 1 Mean (SEM) of the various measures for patients with and without delayed total stomach emptying and patients with and without pathological reflux

\begin{tabular}{|c|c|c|c|c|}
\hline \multirow[b]{2}{*}{ Variable } & \multicolumn{2}{|c|}{ Delayed total emptying } & \multicolumn{2}{|c|}{ Pathological reflux } \\
\hline & Yes $(n=18)$ & No $(n=53)$ & Yes $(n=29)$ & No $(n=42)$ \\
\hline \multicolumn{5}{|l|}{ Gastric emptying } \\
\hline $\mathrm{AUC}_{\text {tot }}$ (units) & $488.2(3.8)$ & $416.9(4.3)$ & $430.5(7.8)$ & $429.0(6.9)$ \\
\hline $\mathrm{AUC}_{\mathrm{prox}}$ (units) & $261.1(22.1)$ & $260.7(9.1)$ & $277.0(15.4)$ & $243.8(9.7)$ \\
\hline $\mathrm{AUC}_{\text {dist }}$ (units) & $227.1(21.8)$ & $156.2(8.9)$ & $153.5(14.3)$ & $185.2(12.0)$ \\
\hline \multicolumn{5}{|l|}{ Gastro-oesophageal reflux } \\
\hline 24 hour acid exposure (\%) & $5.1(1.2)$ & $6.7(1.3)$ & $13.0(1.8)$ & $1.5(0.2)$ \\
\hline Postprandial acid exposure (\%) & $7.1(1.7)$ & $9.1(1.4)$ & $17.1(1.7)$ & $2.5(0.5)$ \\
\hline Reflux episodes/h (n) & $1.4(0.3)$ & $1.7(0.2)$ & $2.9(0.3)$ & $0.7(0.1)$ \\
\hline Oesophagitis (grade) & $0.9(0.3)$ & $1.3(0.2)$ & $2.0(0.2)$ & $0.7(0.2)$ \\
\hline \multicolumn{5}{|l|}{ Oesophageal contractile activity } \\
\hline LOS resting pressure $(\mathrm{mm} \mathrm{Hg})$ & $12.6(1.1)$ & $14.8(0.9)$ & $10.7(0.8)$ & $16.8(0.9)$ \\
\hline Amplitude distal (mm Hg) & $72.7(10.7)$ & $72.3(6.4)$ & $56.1(7.6)$ & $83.6(7.0)$ \\
\hline Amplitude middle (mm Hg) & $55.2(8.2)$ & $55.0(5.2)$ & $41.6(4.9)$ & $64.6(6.1)$ \\
\hline Amplitude proximal (mm $\mathrm{Hg}$ ) & $45.0(7.4)$ & $43.5(2.4)$ & $40.9(3.9)$ & $46.7(3.5)$ \\
\hline Failed contractions (\%) & $8.7(2.4)$ & $8.4(1.8)$ & $10.9(2.8)$ & $6.6(1.6)$ \\
\hline Oesophageal clearance time (s) & $45.3(11.1)$ & $42.9(5.6)$ & $50.8(8.8)$ & $38.7(5.8)$ \\
\hline Age (y) & $46.6(3.2)$ & $52.0(1.7)$ & $52.6(2.2)$ & $49.6(2.1)$ \\
\hline Body mass index $\left(\mathrm{kg} / \mathrm{m}^{2}\right)$ & $23.8(1.0)$ & $26.6(0.5)$ & $26.1(0.7)$ & $25.8(0.7)$ \\
\hline
\end{tabular}

generated. Clearance was assumed to be complete when $95 \%$ of the bolus had entered the fundus (clearance time). None of the patients had a hiatal hernia giving rise to difficulties in the positioning of the three regions of interest over the oesophageal body. In 24 healthy asymptomatic individuals (14 female, 10 male; aged 20-69 years, median 36), clearance time ranged from 5.5 to 12.0 seconds (median 7.3 seconds; 95 th percentile 9.7). A clearance time $>15$ seconds was considered prolonged.

STATISTICAL ANALYSIS

To investigate the relationships between 24 hour and postprandial acid exposure and the number of reflux episodes/hour on the one hand and values recorded for the remaining variables on the other, a correlation analysis was performed. To elucidate the degree to which the dependent variables 24 hour acid exposure and two hour postprandial acid exposure were explained by the independent variables $\mathrm{AUC}_{\text {tot }}, \mathrm{AUC}_{\text {prox }}$, LOS resting pressure, contraction amplitude in the distal, middle, and proximal oesophagus, percentage of failed contractions, clearance time, age and BMI, two multiple linear regression analyses were carried out. The explained portion of the variance in these analyses was calculated by determining the coefficient of determination $r^{2}$. Selection of the independent variables for entry into the model was stepwise with the significance level set at $\mathrm{p}=0.05$.

\section{Results}

Of the 71 patients, 18 had delayed entire stomach emptying, 29 had pathological reflux, and 44 a prolonged oesophageal clearance time. Of the 18 patients with delayed emptying, seven (39\%) had pathological reflux and 10 prolonged clearance time; of the 16 patients with delayed emptying who had undergone oesophagoscopy, eight had oesophagitis. In contrast, of 29 patients with pathological reflux, seven $(24 \%)$ had delayed gastric emptying and 19 prolonged clearance time. Of the 26 patients with no oesophagitis, four had pathological reflux whereas of the 38 patients with oesophagitis, 22 had pathological reflux.

All data subjected to statistical analyses were normally distributed. Mean values of the various measures for patients with and without delayed gastric emptying and patients with and without pathological reflux are shown in table 1. In patients with delayed gastric emptying, $\mathrm{AUC}^{\text {tot }}$ and $\mathrm{AUC}_{\text {dist }}$ were larger than in those with emptying in the normal range, whereas AUC $_{\text {prox }}$ were almost identical (table 1). In patients with pathological reflux, $\mathrm{AUC}_{\text {dist }}$ were smaller and $\mathrm{AUC}_{\mathrm{prox}}$ larger than in those with no pathological reflux, whereas AUC $_{\text {tot }}$ did not differ (table 1). In patients with pathological reflux, LOS pressure and amplitudes of the swallow initiated contractions in the distal and middle thirds of the oesophageal body were markedly lower than in those without pathological reflux; amplitudes in the proximal third, percentage of failed contractions, and clearance time, however, did not differ (table 1). 


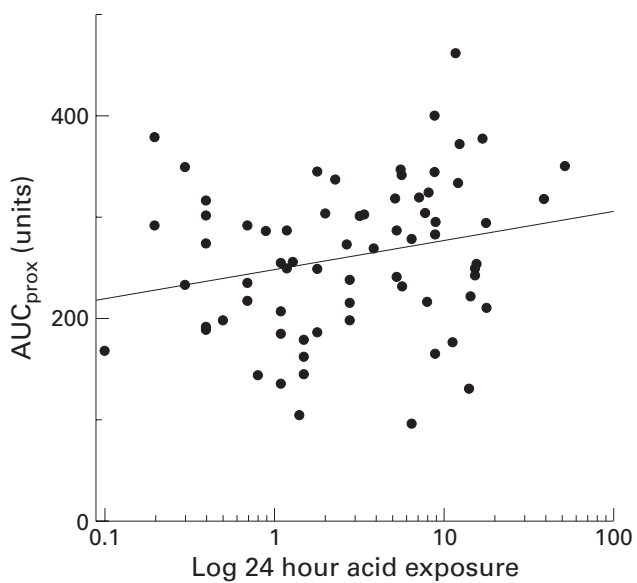

Figure 1 Relationship between proximal stomach emptying $\left(A U C_{\text {pros }}\right)$ and percentage of time spent with $\mathrm{pH}$ $<4$ in the 24 hour recording period (24 hour acid exposure) on a logarithmic scale.

Correlation analyses showed that there were significant relationships between $\mathrm{AUC}_{\mathrm{prox}}$ on the one hand and 24 hour acid exposure (fig 1; table 2) and number of reflux episodes/hour on the other: the slower the proximal emptying, the more 24 hour acid exposure and episodes/hour (table 2). An analogous relationship was found between $\mathrm{AUC}_{\mathrm{prox}}$ and postprandial acid exposure (fig 2; table 2). $\mathrm{AUC}_{\text {tot }}$, by contrast, was not related to 24 hour acid exposure (fig 3; table 2), postprandial acid exposure (fig 4; table 2), or reflux episodes/hour (table 2). Neither proximal nor total stomach emptying was significantly correlated with LOS pressure, contraction amplitude in the distal, middle and proximal oesophagus, percentage of failed contractions, oesophageal clearance time, degree of oesophagitis, or BMI. AUC ${ }_{\text {dist }}$ but not $\mathrm{AUC}_{\text {prox }}$ was significantly correlated with $\mathrm{AUC}_{\text {tot }}(r(69)=0.380$, $\mathrm{p}=0.001$; and $r(69)=0.164, \mathrm{p}=0.171$, respectively). This showed that delayed total stomach emptying was due mainly to retention in the distal stomach. As expected, there was an inverse relationship between $\mathrm{AUC}_{\text {prox }}$ and $\mathrm{AUC}_{\text {dist }}(r$ (69) $=-0.850 ; p=0.0001$ ).

Twenty four hour acid exposure, number of reflux episodes/hour, and postprandial acid

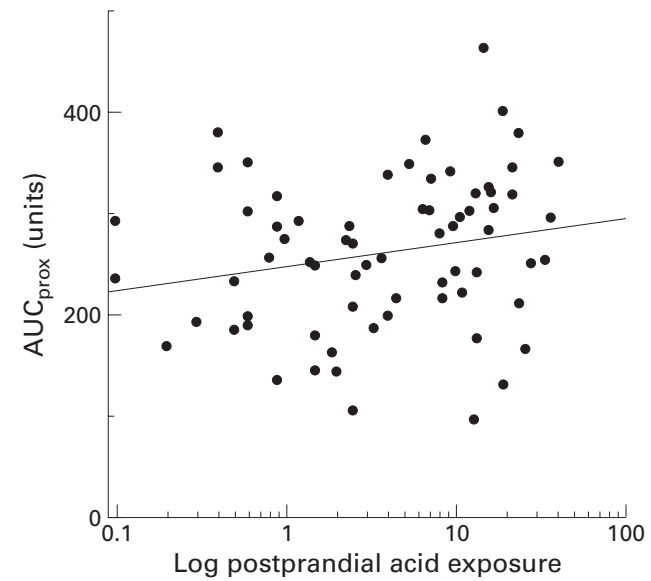

Figure 2 Relationship between proximal stomach emptying $\left(A U C_{\text {proad }}\right)$ and percentage of time spent with $\mathrm{pH}$ $<4$ in the postprandial two hour period (postprandial acid exposure) on a logarithmic scale.

exposure were highly correlated with each other (table 2). Significant inverse relationships were found between both 24 hour and postprandial acid exposure and number of reflux episodes/hour on the one hand and LOS pressure (figs 5, 6; table 2) as well as amplitude of swallow induced pressure waves in the distal and middle parts of the oesophagus on the other (table 2). Both 24 hour and postprandial acid exposure and number of reflux episodes/ hour were significantly correlated with the degree of oesophagitis. Postprandial acid exposure and number of reflux episodes/hour but not 24 hour acid exposure were correlated with percentage of failed contractions (table 2). There was no relationship between reflux activities and amplitude of contractions in the proximal oesophagus, oesophageal clearance time, as well as patient age and BMI (table 2).

Multiple regression analyses revealed that the dependent variable 24 hour acid exposure was explained, to a highly significant degree, by the independent variables LOS pressure and AUC $_{\text {prox }}$. These two variables accounted for $22.4 \%$ and $8.0 \%$, respectively, of the total variance, whereas the remaining eight independent variables together accounted for only $10.8 \%$ of

Table 2 Correlations between 24 hour and postprandial acid exposure and number of reflux episodes/hour on the one hand and total, proximal, and distal stomach emptying, oesophageal contractile activity and clearance, grade of oesophagitis, age, and BMI on the other

\begin{tabular}{|c|c|c|c|c|c|c|}
\hline \multirow[b]{2}{*}{ Variable } & \multicolumn{2}{|c|}{24 hour acid exposure } & \multicolumn{2}{|c|}{ Postprandial acid exposure } & \multicolumn{2}{|c|}{ Reflux episodes $/ h$} \\
\hline & $r(69)$ & $p$ & $r(69)$ & $p$ & $r(69)$ & $p$ \\
\hline \multicolumn{7}{|l|}{ Gastric emptying } \\
\hline $\mathrm{AUC}_{\text {tot }}$ & 0.080 & 0.505 & 0.058 & 0.624 & 0.086 & 0.478 \\
\hline $\mathrm{AUC}_{\mathrm{prox}}$ & 0.256 & 0.031 & 0.229 & 0.055 & 0.251 & 0.035 \\
\hline $\mathrm{AUC}_{\mathrm{dist}}^{\mathrm{pox}}$ & -0.197 & 0.099 & -0.183 & 0.126 & -0.190 & 0.113 \\
\hline \multicolumn{7}{|l|}{ Oesophageal contractile activity } \\
\hline LOS resting pressure & -0.466 & 0.0001 & -0.417 & 0.0003 & -0.509 & 0.0001 \\
\hline Amplitude distal & -0.329 & 0.005 & -0.303 & 0.010 & -0.408 & 0.0004 \\
\hline Amplitude middle & -0.337 & 0.004 & -0.322 & 0.006 & -0.432 & 0.0002 \\
\hline Amplitude proximal & 0.031 & 0.795 & -0.054 & 0.657 & -0.083 & 0.493 \\
\hline$\%$ Failed contractions & 0.155 & 0.196 & 0.253 & 0.034 & 0.290 & 0.014 \\
\hline Oesophageal clearance time & 0.121 & 0.313 & 0.028 & 0.815 & 0.211 & 0.077 \\
\hline \multicolumn{7}{|l|}{ Gastro-oesophageal reflux } \\
\hline 24 hour acid exposure & - & - & 0.808 & 0.0001 & 0.845 & 0.0001 \\
\hline Postprandial acid exposure & 0.808 & 0.0001 & - & - & 0.697 & 0.0001 \\
\hline Oesophagitis & 0.489 & 0.0001 & 0.451 & 0.0002 & 0.474 & 0.0001 \\
\hline Age & 0.053 & 0.881 & 0.066 & 0.588 & 0.050 & 0.685 \\
\hline Body mass index & 0.122 & 0.310 & 0.102 & 0.395 & 0.179 & 0.136 \\
\hline
\end{tabular}

$r$ (69), coefficient of correlation with 69 degrees of freedom; p, error probability. 
the variance (table 3 ). The variables explaining postprandial acid exposure were the same (in the first line LOS pressure and in the second $\left.\mathrm{AUC}_{\mathrm{prox}}\right)$. The respective percentages of total variance were $17.4 \%$ and $6.7 \%$, whereas the

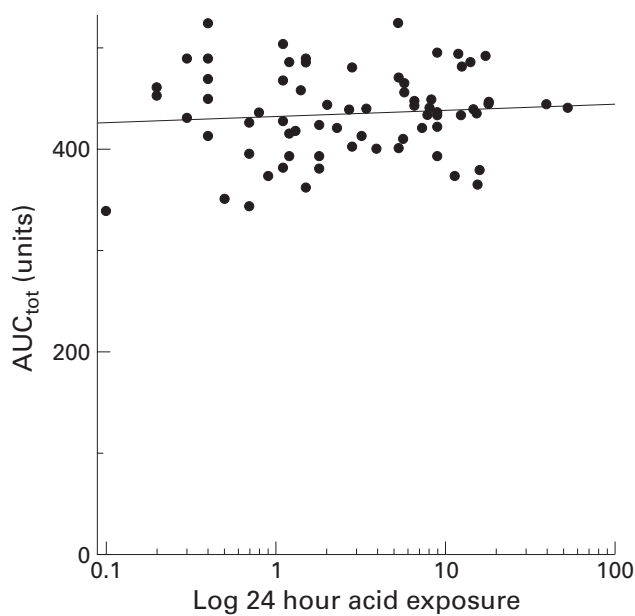

Figure 3 Relationship between total stomach emptying $\left(A U C_{w}\right)$ and percentage of time spent with $\mathrm{pH}<4$ in the 24 hour recording period (24 hour acid exposure) on a logarithmic scale.

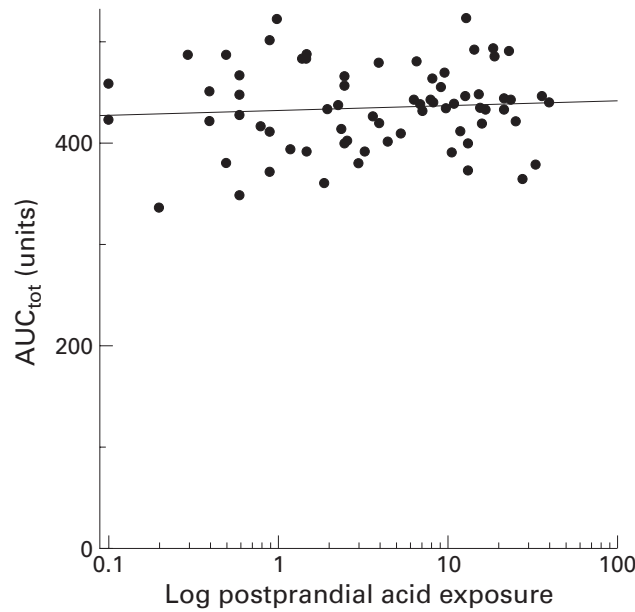

Figure 4 Relationship between total stomach emptying $\left(A U C_{t o}\right)$ and percentage of time spent with $\mathrm{pH}<4$ in the postprandial two hour period (postprandial acid exposure) on a logarithmic scale.

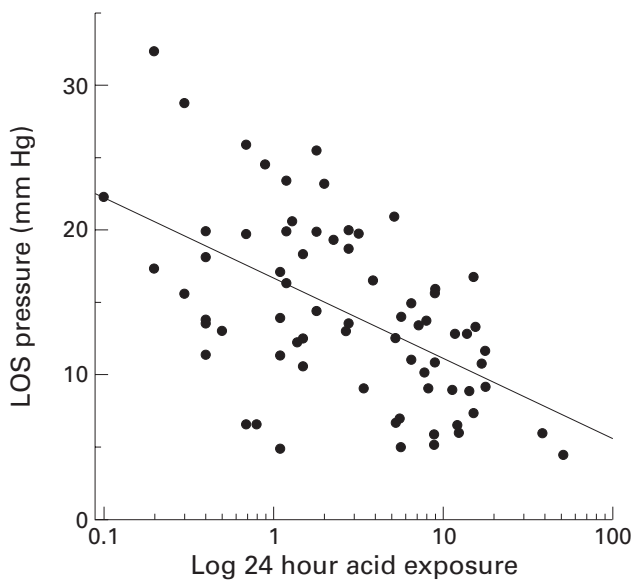

Figure 5 Relationship between lower oesophageal sphincter (LOS) resting pressure and percentage of time spent with $\mathrm{pH}<4$ in the 24 hour recording period (24 hour acid exposure) on a logarithmic scale.

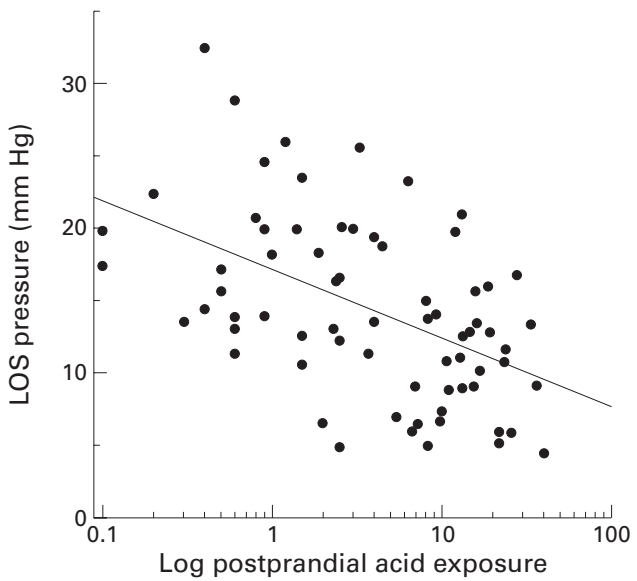

Figure 6 Relationship between lower oesophageal sphincter (LOS) resting pressure and percentage of time spent with $\mathrm{pH}<4$ in the postprandial two hour period (postprandial acid exposure) on a logarithmic scale.

remaining eight independent variables together explained only another $14.6 \%$ (table 3 ). None of the latter variables was found to account for sufficient variance to be selected for entry into the model of the two analyses.

\section{Discussion}

The results of the present study demonstrate that the rate of gastric emptying may contribute to the extent of 24 hour as well as postprandial acid exposure. However, it was not emptying of the entire stomach but only of the proximal part (that is, the fundus and upper corpus) which was revealed to be important for the extent of reflux. These findings are consistent with a report on 16 patients with reflux disease that showed that there was a correlation between the emptying rate of the proximal, but not the total, stomach and number of transient LOS relaxations in the postprandial period. ${ }^{18}$ Delayed proximal stomach emptying and increased number of transient LOS relaxations leading to increased reflux may be interrelated and result from an abnormally slow recovery of gastric tone in response to distension, as suggested by a recent study. ${ }^{24}$ The results of the multiple regression analyses carried out in the present investigation showed that the impact of proximal stomach emptying on the extent of reflux was far less prominent than that of LOS pressure. This was indicated also by the observation that 17 of 29 patients with pathological reflux had low LOS pressure $(<12 \mathrm{~mm} \mathrm{Hg}$ ) but only seven had delayed total stomach emptying. Proximal stomach emptying, however, was markedly slower in patients with pathological reflux than in those without and correlated significantly with both 24 hour acid exposure and number of reflux episodes/hour, which may have resulted mainly from transient LOS relaxations. ${ }^{19}$ In contrast with other workers, ${ }^{1617}$ we could not reveal differential effects of total or proximal stomach emptying on 24 hour acid exposure as opposed to postprandial acid exposure: the factors which correlated with reflux occurring in both time spans were primarily LOS pressure and, in the second, proximal stomach emptying. No rela- 
Table 3 Results of multiple regression analyses investigating the degree to which the dependent variables 24 hour and postprandial acid exposure were explained by independent variables

\begin{tabular}{|c|c|c|c|c|c|}
\hline $\begin{array}{l}\text { Dependent variable } \\
\text { (acid exposure) }\end{array}$ & $\begin{array}{l}\text { Independent } \\
\text { variable }\end{array}$ & Regression coefficient $\beta$ & $\begin{array}{l}\text { Standard } \\
\text { error of } \beta\end{array}$ & $\begin{array}{l}\text { Error } \\
\text { probability }\end{array}$ & $\begin{array}{l}\text { Variance } \\
\text { accounted for }(\%)\end{array}$ \\
\hline \multirow[t]{2}{*}{24 hour } & LOS pressure & $-0.807 \% / \mathrm{mm} \mathrm{Hg}$ & 0.145 & 0.0001 & 22.4 \\
\hline & $\mathrm{AUC}_{\mathrm{prox}}$ & $0.004 \% /$ unit & 0.001 & 0.0007 & 8.0 \\
\hline \multirow[t]{2}{*}{ Postprandial } & LOS pressure & $-0.742 \% / \mathrm{mm} \mathrm{Hg}$ & 0.169 & 0.0001 & 17.4 \\
\hline & $\mathrm{AUC}_{\text {prox }}$ & $0.004 \% /$ unit & 0.001 & 0.0071 & 6.7 \\
\hline
\end{tabular}

tionship between total stomach emptying and reflux was found in earlier studies carried out in $48^{6}$ and 32 patients ${ }^{25}$ with reflux disease.

The finding of the present study that neither total nor proximal stomach emptying was related significantly to the percentage of failed contractions and oesophageal clearance time contrasts with results of an earlier investigation in 105 patients with chronic reflux. ${ }^{26}$ In these patients, delayed total stomach emptying was closely associated with impaired oesophageal clearance of a solid bolus and the frequency of failed primary oesophageal peristalsis; the latter phenomenon, however, was present in only $17 \%$ of patients. ${ }^{26}$

The observed correlation between extent of both 24 hour and postprandial acid exposure and degree of oesophagitis is consistent with the results of a number of earlier investigations ${ }^{6} 81213$ but contrasts with others. ${ }^{10141527}$ The discrepancy may be explained by the comparatively small numbers of patients studied by authors having found no difference in acid exposure between reflux patients with and without oesophagitis, ${ }^{27}$ between patients with oesophagitis and healthy subjects ${ }^{1014}$, or between patients with severe versus moderate oesophagitis. ${ }^{28}$ That patient age and BMI had no significant influence on either 24 hour or postprandial acid exposure is in agreement with earlier observations: in 353 patients, age was found not to be a determinant of 24 hour acid exposure $^{29}$ and 50 massively obese patients had no more reflux than 29 age and sex matched healthy, non-obese subjects. ${ }^{30}$

Although in the present study recordings of gastric emptying, oesophageal contractile and gastro-oesophageal reflux activity, and oesophageal clearance function were carried out on separate days rather than concurrently, and these functions may vary from day to day in a given subject, we conclude that emptying of the proximal stomach, but not the total stomach, may contribute to the extent of 24 hour as well as postprandial acid exposure and number of reflux episodes/hour.

1 Holloway RH, Hongo M, Berger K, et al. Gastric distention: a mechanism for postprandial gastroesophageal reflux. Gastroenterology 1985;89:779-84.

2 Holloway RH, Kocyan P, Dent J. Provocation of transient lower esophageal sphincter relaxations by meals in patients with symptomatic gastroesophageal reflux. Dig Dis Sci with symptomatic

3 McCallum RW, Berkowitz DM, Lerner E. Gastric emptying in patients with gastroesophageal reflux. Gastroenterology 1981;80:285-91.

4 Maddern GJ, Chatterton BE, Collins PJ, et al. Solid and liquid gastric emptying in patients with gastrooesophageal reflux. Br F Surg 1985;72:344-7.

5 Papaila JG, Wilmot D, Grosfeld JL, et al. Increased incidence of delayed gastric emptying in children with gastroesophageal reflux. Arch Surg 1989;124:933-6

6 Cunningham KM, Horowitz M, Riddell PS, et al. Relations among autonomic nerve dysfunction, oesophageal motility, and gastric emptying in gastro-oesophageal reflux disease. Gut 1991;32:1436-40.

7 Scarpignato C, Franze A. Esophageal exposure to acid in GERD patients with and without delayed gastric emptying. Effect of cisapride. Hepatogastroenterology 1992;39:91-2.

8 Salvioli B, Tosetti C, Stanghellini V, et al. Gastric emptying, acid secretion and dyspeptic symptoms in reflux esophagitis (abstract). Neurogastroenterol Mot 1996;8:189.

9 Soykan I, Lin Z, Jones S, et al. Gastric myoelectrical activity, gastric emptying and correlations with dyspepsia symptoms in patients with gastroesophageal reflux. F Invest Med 1997;45:483-7.

10 Shay SS, Eggli D, McDonald C, et al. Gastric emptying of solid food in patients with gastroesophageal reflux. Gastroenterology 1987;92:459-65.

11 Schwizer W, Hinder RA, DeMeester TR. Does delayed gastric emptying contribute to gastroesophageal reflux disease? Am 7 Surg 1989;157:74-81.

12 Corinaldesi R, Mattioli S, Stanghellini V, et al. Gastric acid secretion and emptying of solids and liquids in patients with severe reflux esophagitis (abstract). Gastroenterology 1989;96:A100.

13 Cucchiara S, Minella R, Campanozzi A, et al. Effects of omeprazole on mechanisms of gastroesophageal reflux in childhood. Dig Dis Sci 1997;42:293-9.

14 Csendes A, Henriquez A. Gastric emptying in patients with reflux esophagitis or benign strictures of the esophagus Secondary to reflux compar

15 Keshavarzian A, Bushnell DL, Sontag S, et al. Gastric emptying in patients with severe reflux esophagitis. $A m$ f Gastroenterol 1991;86:738-42.

16 Hillemeier AC, Grill BB, McCallum R, et al. Esophageal and gastric motor abnormalities in gastroesophageal reflux during infancy. Gastroenterology 1983;84:741-6.

17 Carroccio A, Iacono G, Li Voti G, et al. Gastric emptying in infants with gastroesophageal reflux. Ultrasound evaluation before and after cisapride administration. Scand F Gastroenterol 1992;27:799-804.

18 Lundell L, Anvari M, Collins PJ, et al. The association between gastric emptying, gastric distension and transient lower esophageal sphincter relaxations in patients with gastroesophageal reflux disease (abstract). Gastroenterology 1992;102:A478.

19 Dent J, Holloway RH, Toouli J, et al. Mechanisms of lower oesophageal sphincter incompetence in patients with symptomatic gastrooesophageal reflux. Gut 1988;29:10208.

20 Savary M, Miller G. Der Ösophagus. Lehrbuch und endoskopischer Atlas. Solothurn: Gassmann, 1977.

21 Stacher G, Bergmann H, Wiesnagrotzki S, et al. Intravenous cisapride accelerates delayed gastric emptying and increases antral contraction amplitude in patients with primary anorexia nervosa. Gastroenterology 1987;92:10006.

22 Collins PJ, Horowitz M, Chatterton BE. Proximal, distal and total stomach emptying of a digestible meal in normal subjects. Br F Radiol 1988;61:12-8.

23 Johnson LF, DeMeester TR. Twenty-four-hour pH monitoring of the distal esophagus. A quantitative measure of gastroesophageal reflux. Am $\mathcal{f}$ Gastroenterol 1974;62:32532 .

24 Penagini R, Hebbard G, Horowitz M, et al. Motor function of the proximal stomach and visceral perception in gastroof the proximal stomach and visceral perception
oesophageal reflux disease. Gut 1998;42:251-7.

25 Kamberoglou D, Psichos A, Georgiou S, et al. Correlation between esophageal clearance and esophageal motility in patients with gastroesophageal reflux (GER) (abstract). Gut 1996;39(suppl 3):A199.

26 Lundell L, Myers JC, Jamieson GG. Is motility impaired in the entire upper gastrointestinal tract in patients with gastro-oesophageal reflux disease? Scand f Gastroenterol 1996;31:131-5.

27 Cadiot G, Bruhat A, Rigaud D, et al. Multivariate analysis of pathophysiological factors in reflux oesophagitis. Gut 1997;40:167-74.

28 Cucchiara S, Salvia G, Borrelli O, et al. Gastric electrical dysrhythmias and delayed gastric emptying in gastro-
esophageal reflux disease. Am $\mathcal{f}$ Gastroenterol 1997;92: esophagea

29 Ter R, Johnston BT, Castell DO. Influence of age and gender on gastroesophageal reflux in symptomatic patients (abstract). Gastroenterology 1995;108:A238.

30 Lundell L, Ruth M, Sandberg N, et al. Does massive obesity promote abnormal gastroesophageal reflux? Dig Dis Sci 1995;40:1632-5. 